\title{
Design and Analysis of Foot Orthotic For Lower Limb Deformities Using Composites
}

Sunil Kumar Sahu', Manas Ranjan Sahoo ${ }^{2}$

${ }^{1}$ Asst.Professor, Dept. of Mechanical Engineering, Gandhi School of Engineering, Berhampur, Odisha, India

${ }^{2}$ Asst.Professor, Dept. of Mechanical Engineering, Srinix College of Engineering, Balasore, Odisha, India sunil88.mechanical@gmail.com ${ }^{1}$

\begin{abstract}
This research details a procedure for the systematic design of foot orthotics based on simulation models and validation of the same with subsequent experiment. The present model may ultimately to replace the use of empirical tables for the designing of foot orthotics in accordance to the weight and activities of end-users. This present model is so general that it can simulate different kind of orthotics, loading conditions and material properties to give the desired output. Finally, the proposed model and the corresponding results may lead to the form of design basis for new generation foot orthotics. The methodical approach to the development of engineering analysis models using the FEA technique. Orthotic devices have been commonly made from plastics like polypropylene. However, insufficient mechanical properties, labour intensive preparation process, long client's visiting times urge us to seek an alternative. Presently, two different advanced composite materials (Glassfiber, Basalt-fiber) have been chosen for the analysis purpose to achieve the low weight and High Strength.
\end{abstract}

\section{Keywords: Foot Orthotic, Glass Fiber, Basalt Fiber, FEA - ANSYS}

\section{Introduction}

Orthotic devices have been commonly made from plastics like polypropylene. However, insufficient mechanical properties, labour intensive preparation process, long client's visiting times urge us to seek an alternative. An orthotic device made from a composite material is expected to overcome the aforementioned shortcomings by allowing the shaping and hardening of the orthoses to be performed during one fitting directly on the patient. This research examines the mechanical properties of the composite material made with woven fabric and a custom light-curable resin designed specifically for orthotic applications. So, we selected to types of composites such as:

1. Glass-fiber

\section{Basalt-fiber of the paper}

\subsection{Glass Fiber}

Glass fiber is formed when thin strands of silica-based or other formulation glass are extruded into many fibers with small diameters suitable for textile processing. The technique of heating and drawing glass into fine fibers has been known for millennia; however, the use of these fibers for textile applications is more recent. Until this time, all glass fiber had been manufactured as staple (that is, clusters of short lengths of fiber).

The modern method for producing glass wool is the invention of Games Slayter working at the Owens-Illinois Glass Co. (Toledo, Ohio). He first applied for a patent for a new process to make glass wool in 1933. The first commercial production of glass fiber was in 1936. In 1938 Owens-Illinois 


\section{www.rspsciencehub.com}

Glass Company and Corning Glass Works joined to form the Owens-Corning Fiberglas Corporation. When the two companies joined to produce and promote glass fiber, they introduced continuous filament glass fibers [3]. Owens-Corning is still the major glass-fiber producer in the market today [1].

\subsubsection{Composition}

The most common types of glass fiber used in fiberglass is E-glass, which is alumino-borosilicate glass with less than $1 \%$ w/w alkali oxides, mainly used for glass-reinforced plastics. Other types of glass used are A-glass (Alkali-lime glass with little or no boron oxide), E-CR-glass (Electrical/Chemical Resistance; alumino-lime silicate with less than $1 \%$ w/w alkali oxides, with high acid resistance), C-glass (alkali-lime glass with high boron oxide content, used for glass staple fibers and insulation), D-glass (borosilicate glass, named for its low Dielectric constant), Rglass (alumino silicate glass without $\mathrm{MgO}$ and $\mathrm{CaO}$ with high mechanical requirements as reinforcement), and S-glass (alumino silicate glass without $\mathrm{CaO}$ but with high $\mathrm{MgO}$ content with high tensile strength) [6].

\subsection{Basalt Fiber}

Basalt is a type of igneous rock formed by the rapid cooling of lava at the surface of a planet. It is the most common rock in the Earth's crust [4]. Basalt rock characteristics vary from the source of lava, cooling rate, and historical exposure to the elements. High quality fibers are made from basalt deposits with uniform chemical makeup.

\subsubsection{Composition}

Basalt fibers have similar chemical components and mechanical properties as glass fibers. Basalt has a brown color whereas glass fiber is usually much lighter in color. Synthetic fibers: they are polyaramid fibers, such as Kevlar [5], a polymer that is stiffened by benzene rings. They have cost, strength and stiffness intermediate between glass and carbon with low density. They are tougher than glass and carbon fibers but more difficult to cut and weak in compression. They do not bond as well to conventional matrix like epoxy and vinyl ester so the choice of sizing or finish is very important [2].

\section{EXPERIMENTAL DETAILS}

\subsection{Introduction}

In the research point of view we have done two types of experiments such as tensile test and three point bending test on both the composite specimen prepared as per ASTM (American Society for
Testing and Materials) standards and simulated the prepared model on ANSYS by putting the values which we have got from the specimen tests and then got some conclusions.

\subsection{Specimen Preparation}

The method that is used in the present work for manufacturing the laminated composite plates is Hand Layup and Bag Molding \& Curing process. Hand Layup is the oldest method that was used to get the composite materials. The type of Glass Fiber mat selected to make specimens was, Mat-330GSM. The matrix material used was a medium viscosity epoxy resin (LAPOX L-12) manufactured by ATUL India Ltd, Gujarat, India and MS normal hardener (2K), manufactured by PPG Asian Paints Private Limited, kanchipuram, Tamilnadu, India. This matrix was chosen since it provided good resistance to alkalis and has good adhesive properties. Based on volume fraction the calculations were made for 60-40 (60\% Glass Fiber/Basalt Fiber - 40\% Epoxy Resin) combination showed a better result.

\subsubsection{Specimen Preparation Methodology}

The laminated composite plates (Glass fiber and Basalt fiber) of area 1 square feet each has been made by both Hand Layup and Bag Molding and Curing Process and after that from the composite plates the required samples for Tensile test and Three Point Bending Test are cut according to ASTM standard of D-6272.

Table.1. Test Specimen details

\begin{tabular}{|c|c|c|}
\hline Test specimens & ASTM & \multicolumn{1}{|c|}{ Size } \\
\hline $\begin{array}{c}\text { Tensile } \\
\text { test specimens }\end{array}$ & D-6272 & $\begin{array}{l}50 \times 12.7 \times 1.5 \\
\mathrm{~mm} .\end{array}$ \\
\cline { 1 - 1 } $\begin{array}{c}\text { Bending } \\
\text { test specimens }\end{array}$ & & \\
\hline
\end{tabular}

\section{Step-1:}

Mixed the Epoxy Resin, accelerator and Hardener at a ratio of 3:1:2 and the resin system were mixed for $20 \mathrm{~min}$ by hand and left it for $10 \mathrm{~min}$ for evacuation of air bubbles from the mixture.

\section{Step-2:}

Since we are prepared the laminated FRP composite plates (for both Glass fiber and Basalt fiber) in open mold shape so Hand layup process and vacuum bag process is used. Applied the 
www.rspsciencehub.com

releasing agent (wax) for surface finish, then fiberglass reinforcement is placed in the mould; base resin mixed with catalysts is applied by brushing. Layup is made by building layer upon layer (4 layers) to obtain the desired thickness. This process takes 4-5 days of curing at room temperature.

Step-3: So bag molding (vacuum bag molding) is used as a supplementary process to curing in this process the total mould is covered by a covering film and before the covering film some tissue paper is placed upon a purported film to extract the excess amount of resin from the composite to curing when the sealed mould is connected by the vacuum extraction pump the pressure limit is minimum of $80 \mathrm{Kpa}$ for glass fiber composite and $90 \mathrm{Kpa}$ for basalt fiber. Now keep the process continued for $24 \mathrm{hrs}$ to cure the resin and the resin will distribute uniformly throughout the whole surface.

\section{Step-4:}

After completion of $24 \mathrm{hrs}$ the composite will be extracted from the mould and cut the specimens as per ASTM D-6272 for Tensile test and 3-point Bending test by the help of jig saw cutter for Glass fiber composite and shear cutter for Basalt fiber composite shown in figure 1 .
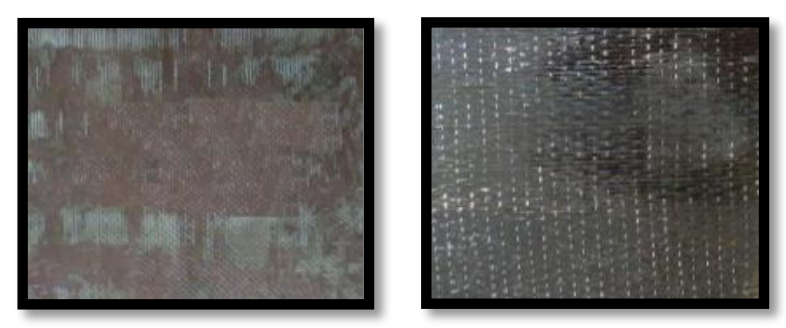

Fig.1. Composite of Glass \& Basalt Fiber
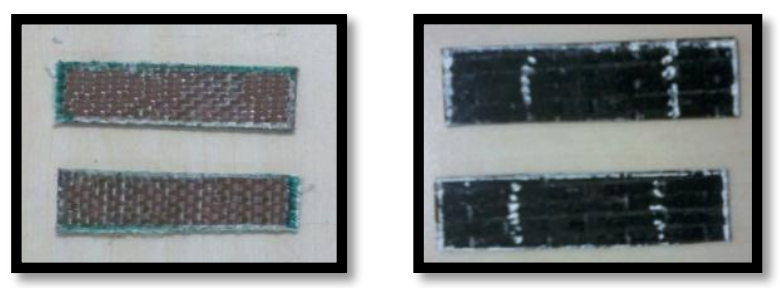

Fig.2. Specimen of Glass \& Basalt Fiber 2.2.2 Tensile Test of samples: The samples were tested by the UTM (INSTRON, SATEC, 600KN).
Volume 02 Issue 08 August 2020

From the tested specimens of basalt fiber and glass fiber we got the difference that the samples were extended by length and after that it cracks shown in the Figure.3. $a \& b$.
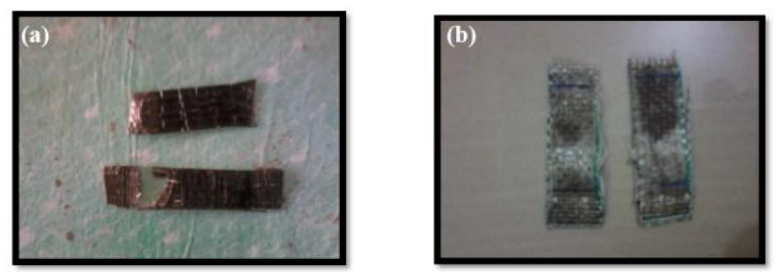

Fig.3. Tested Specimen of Basalt \& Glass Fiber

\subsubsection{Three-point Bending Test of samples}

For the bending analysis, the three-point bend test has been performed on a woven 4-layered crossply $\left(0^{\circ} / 90^{\circ}\right)$ glass/epoxy laminated composite panel, using UTM (INSTRON 5967) with environmental chamber to determine the static responses.

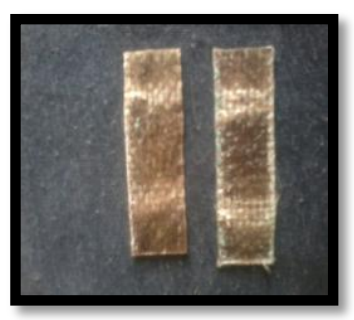

Fig.4. after bending test of glass fiber

Two samples have taken into consideration for the bending test. The tested sample has shown above (Fig.4). The details about these samples have elaborated in further discussion.

\section{Result and Discussion}

\subsection{Tensile Test:}

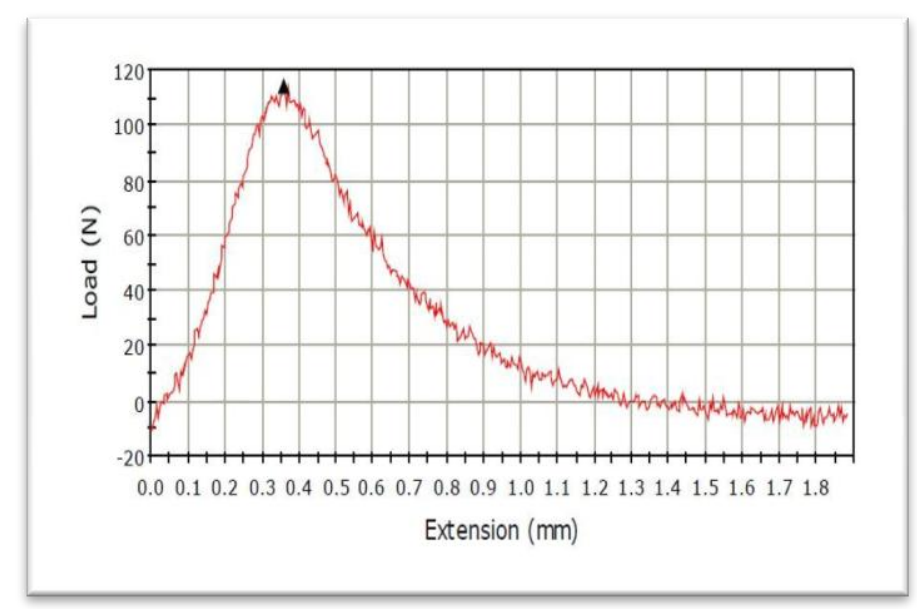

Fig.5.Tensile test of Glass fiber composite specimen 
www.rspsciencehub.com

From the tested specimens of glass fiber, a graph of Load vs. Extension is plotted as shown in the Figure.5. It has been calculated that the maximum load can sustain by the glass fiber composite is $110 \mathrm{~N}$ with respect to corresponding change in dimension of $0.35 \mathrm{~mm}$. After that the load decreases and remains unchanged at approximate $1.4 \mathrm{~mm}$ of extension but the extension continues to increases and at last finally some cracks appeared in the composite specimen along the crossection and a white line appears at the centre of the specimen.

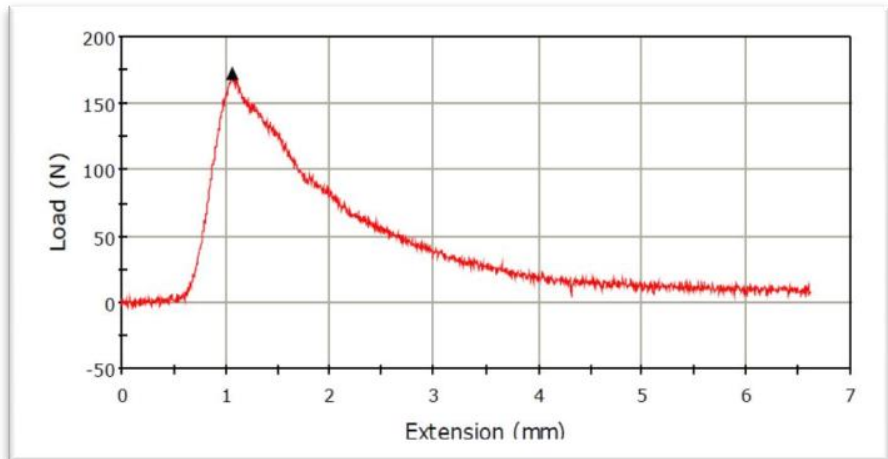

Fig.6. Tensile test of Basalt fiber composite specimen

From the Fig. 6 it has been observed that the basalt fiber composite can sustain a maximum load of $158 \mathrm{~N}$ with respect to corresponding change in dimension of $1.1 \mathrm{~mm}$. After that further increased in extension leads to decreases the load and after a certain period of time the load remains constant but the specimen continue to deform.Further comparison of load vs. extension of both the fiber composites will depicts that under same loading condition the glass fiber is stiffer than basalt fiber composite shown in fig.7.

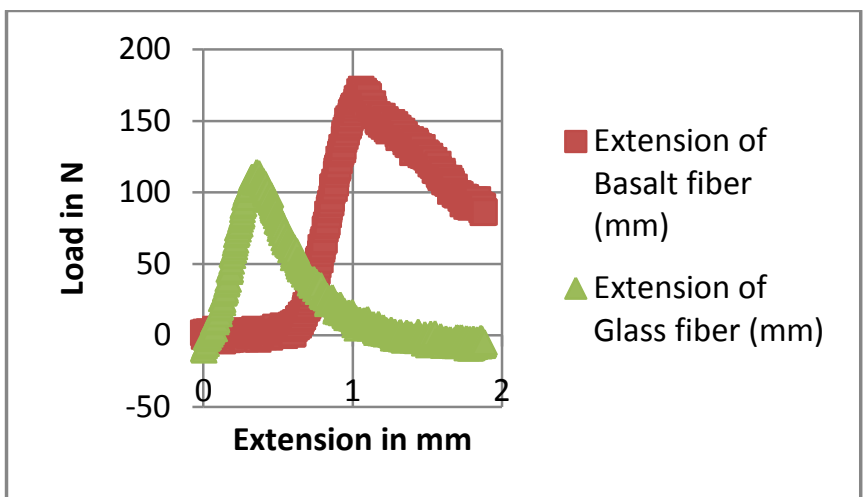

Fig.7. Tensile test comparison of Glass Fiber \& Basalt fiber composite specimen
Volume 02 Issue 08 August 2020

\subsection{Three-point Bending test:}

From the test it is observed that the flexural stress is increases as flexural strain increases at a certain flexural strain. The flexural stress will get decreased after a certain interval of time and the flexural stress will get constant while flexural strain still increasing as shown in the graph Fig.8.

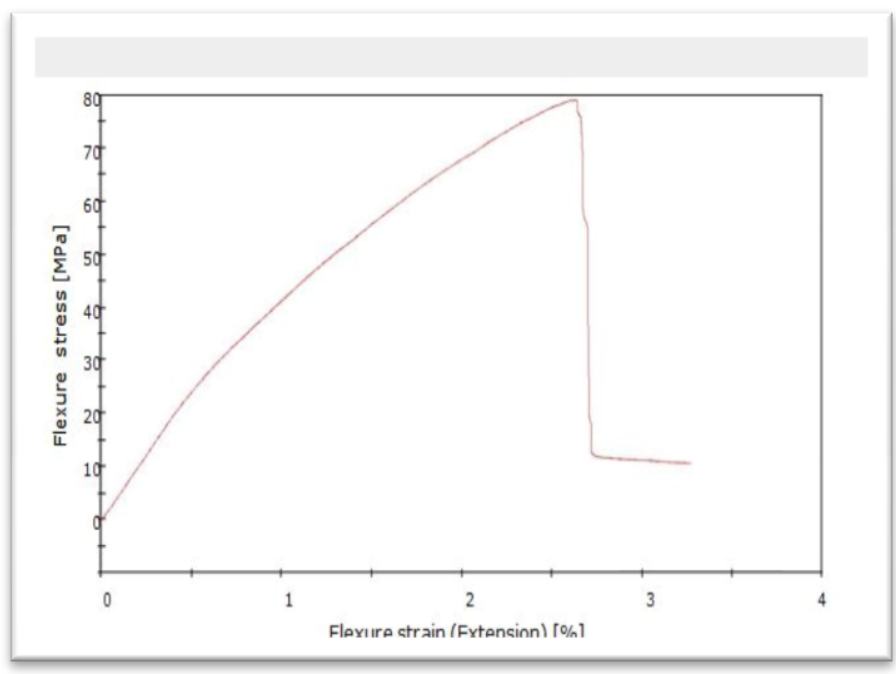

Fig.8. Three-point Bending test of glass fiber composite

It was interesting to note that a "whitening", phenomenon in the areas under the load noses was observed after the yielding point for the composite specimens. As can be seen from Figure.18, two small separated whitening areas were seen on each specimen, whitening areas did not spread along lengthwise direction.It was also noted that no brittle fracture was observed for the composite specimens, it is conjectured that this is due to the existence of the entrapped air bubbles as they may make composites less brittle, no obvious fiber breakage was observed on either side. The composite samples tested remained integrated and no separation was found, suggesting they were non-brittle in nature.

\section{Analysis using ANSYS}

\subsection{Introduction}

The proposed model of lower limb foot orthotic will be created by solid modeling and simulated in ANSYS 15.0 by putting the required properties of glass fiber and applied different conditions such as lower part should be kept fixed and force / 


\section{www.rspsciencehub.com}

pressure will be applied on the upper part of the proposed model shown in Figure 9.

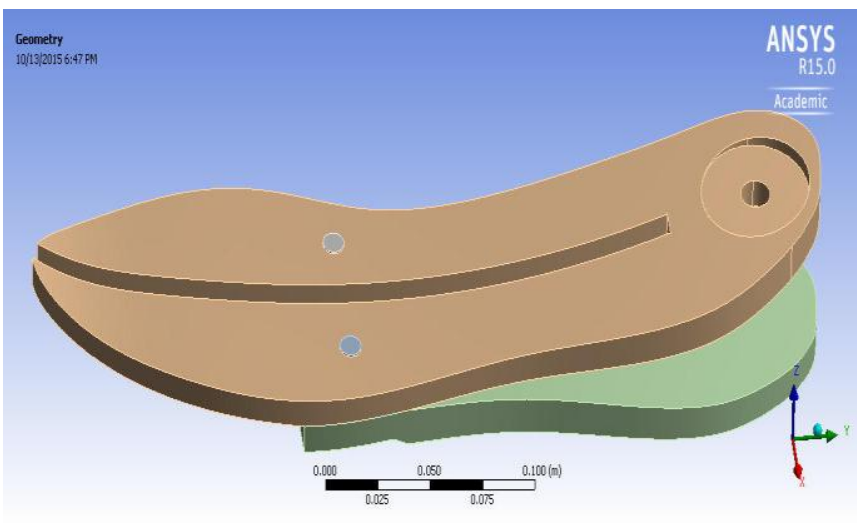

Fig.9. Proposed Model

In fig.9, it is shown that how the bolt is fixed to the lower part and upper part of the model and the contact region of lower part of upper surface and upper part of lower surface.

\subsection{Mesh of element for simulation}

In the present analysis the Cartesian co-ordinate system is used and the elements meshed to the model (Fig.10), here the elements used as 4node 181 types. Total no of element meshed is 17384 triangular type and nodes created as 31078 .

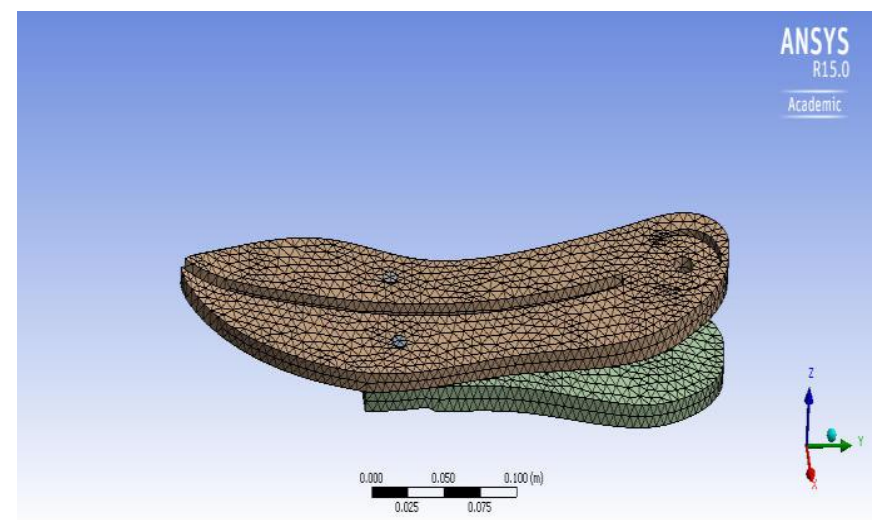

Fig.10. Meshed model

\author{
Material data taken for simulation \\ Compressive Yield Strength $\mathrm{Pa}-1.08 \mathrm{e}+009$ \\ Tensile Yield Strength $\mathrm{Pa}-3.445 \mathrm{e}+009$ \\ Tensile Ultimate Strength $\mathrm{Pa}-3.445 \mathrm{e}+009$ \\ 4.3 Models after Simulation:
}
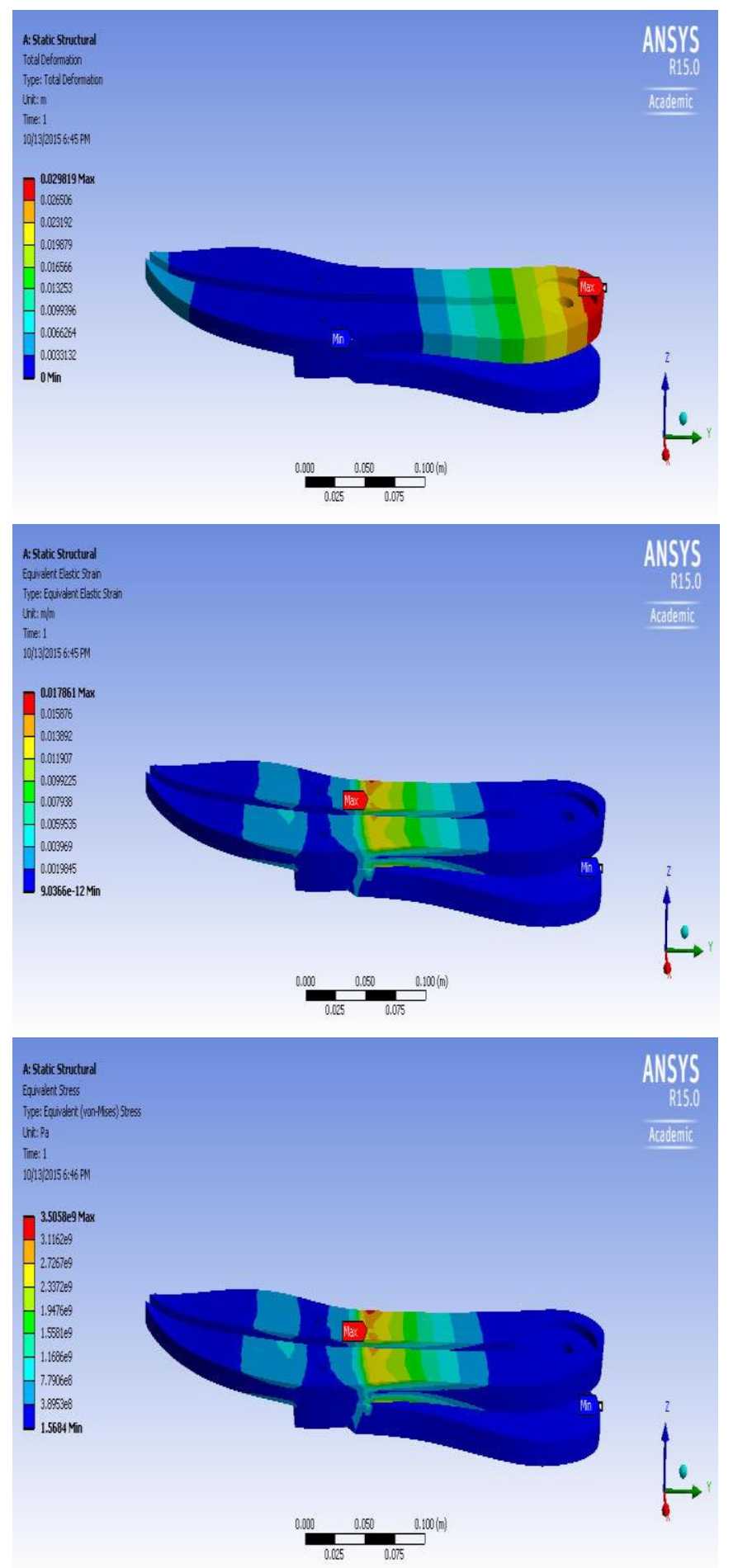

Fig.11.Models after Simulation

In the static structural simulation model the maximum equivalent elastic strain appears at both the contact region- 1 and contact region- 2 and minimum at the heel region and equivalent (vonmises) stress also as same as the equivalent elastic strain.But in case of total deformation the maximum deformation at heel edge region where as minimum at the mid-stance region of the model. 


\section{Conclusions}

From the tensile test it concluded that the glass fiber can resist more load as compared to the basalt fiber an get less deformed as compared to the basalt fiber and It is also concluded that glass fiber is so much of stiff as compared to basalt fiber. From the three points bending test of glass fiber it is concluded that the glass fiber is ductile in nature.

From the simulation of the model in ANSYS we got that Equivalent elastic strain maximum at the contact regions that is $0.017861 \mathrm{~m} / \mathrm{m}$ and minimum at the heel region that is $9.0366 \mathrm{e}-$ 12.Equivalent (von-Mises) stress maximum at the contact regions that is $3.5058 \mathrm{e} 9$ and minimum at the heel region that is 1.5689 pa.Total deformation maximum at heel edge region that is $0.029819 \mathrm{~m}$ and minimum at the mid-stance region that is 0 .

\section{Acknowledgement (Optional)}

I am very much thankful to my parents \& my wife for motivating me to do hard work.

\section{References}

\section{Journals}

[1] Method \& Apparatus for Making Glass Wool", published 11 Nov 1933, issued 11 Oct 1938

[2] Bader, M.G., Smith, Wilburn, Isham, Allan B., Rolston, J. Albert, Metzner, Arthur B., Delaware Composites Design Encyclopedia. Processing and Fabrication Technology. Vol. 3. 1990.

\section{Book}

[3] Nawy, Edward G. (2001). Fundamentals of high-performance concrete (2 ed.). John Wiley and Sons. p. 310. ISBN 978-0-47138555-4.

\section{Chapter in a Book}

[4] Hancock, Paul and Skinner, Brian J. "basalt." The Oxford Companion to the Earth. 2000. Encyclopedia.com.

[5] Hull, D., An Introduction to Composite Materials. 1985, New York, NY: Cambridge University Press.
[6] Marsh, George (8 Oct 2006). "50 years of reinforced plastic boats". reinforced plastics. Elsevier Ltd.

\section{Conference Proceedings}

